\title{
Development and validating procedure of a formula to calculate a minimum separation distance from piggeries and poultry facilities to sensitive receptors
}

Jacques Nicolas, Julien Delva, Pierre Cobut, Anne-Claude Romain

University of Liège, Department "Environmental Sciences and Management," Research Group "Environmental monitoring, "Avenue de Longwy 185, B6700 Arlon, Belgium

\begin{abstract}
A specific formula to calculate separation distance from piggeries and poultry facilities to sensitive receptor is developed for Walloon Region, in Belgium. The paper briefly presents the main principles of the formula and discusses more deeply the compatibility of the distance approach with odour units, odour rate and percentiles usually applied to assess the odour annoyance zones. A method of validation is presented and tested to adjust the different parameters of the formula to Belgian field reality. A total of 43 farms of which 21 piggeries and 22 poultry facilities are visited and, for each case, the distance calculated by the formula is compared to the one deduced from odour annoyance criterion $\left(10 \mathrm{ou} \mathrm{m}^{-3}\right.$ at 98 th percentile). Validation work results in discussing the sensibility of different factors of the formula and especially in adjusting a fitting factor to match the absolute distances to real field annoyance impression. Conclusions show that both approaches - separation distance formula and percentile evaluation - are coherent. The validation method allows parameter adjustment but should need further refinements to examine separately piggeries and poultry facilities.
\end{abstract}

Keywords: Odour management, Setback distance, Atmospheric dispersion modeling, Pigs, Poultry

\section{Introduction}

The intensification of agricultural enterprises and urban development has led to an increase in conflicts between farmers and residents. Such conflict arises mainly from the odour generated by animal husbandries, especially by piggeries and poultry facilities.

Good planning is a major contributing factor to prevent complaints and to minimise instances of incompatible residential areas locating adjacent to agricultural operations in a manner that inhibits normal farming practice.

Land use planning guidelines generally include the calculation of a minimum separation distance, or buffer zone, between the agricultural enterprise and the closest residential area. A lot of formulas are proposed in many countries and comparisons between national guidelines are extensively discussed in the literature (Guo et al., 2004; Preston and Furberg, 2006; Schauberger et al., 2001 ; Van Harreveld and Jones, 2001 ).

All models aim at assessing a minimum separation distance using an equation with a number of factors that depend on the type of animal, the size and characteristics of the operation (e.g. type of manure) and possibly topography, landscape or meteorology. Though being currently applied for everyday legislation purpose, those simple formulas still need further validation against more sophisticated dispersion models or against outcomes of surveys in the surrounding area of livestock buildings. Most guidelines were already empirically derived on the basis of practical field surveys (VDI, 2001), some of them were analysed and sometimes adapted by subsequent studies (Bongers et al., 2001 ). Many interesting works compare also the buffer zone approach to the area delimited by a percentile calculated by an atmospheric dispersion model (Schauberger et al., 2001; Hayes et al., 2006). They constitute powerful tools for further investigation.

The present paper concerns a study carried out in the frame of a request of the Government of the Walloon Region in Belgium. It entrusted our research team with inventory and test of the various guidelines related to the calculation of the minimum distance to recommend between livestock buildings (especially pig and poultry breeding cases) and dwellings to ensure a level of acceptability of the generated odour. Eight formulas applied in various countries were examined and compared and sensitivity study of the various parameters was undertaken. 
That first comparison gave rise to the appreciation of the various methodologies, according to criteria relevant to field reality, technical feasibility, applicability to the Walloon region and coherence with the theories of odour generation and dispersion. The study lasted about three years, during which not only livestock management processes changed, but also the associated evaluation methods and criteria have undergone further development and refinement (VDI, 2001). Recently, many countries proposed odour regulation based on the exposition concept, evaluated by a percentile compliance exceeding probability for a given receptor odour concentration (see, e.g. http://www.odournet.com/legislation.html, consulted in January 2008). Such policies, generally recommended for industrial odour sources, must be compatible with the minimum distance formula proposed for agricultural enterprises.

On the basis of those various elements, an original formula was proposed in 2006. The various parameters of this formula were adjusted thanks to field inspections. Then, the formula was validated on real agricultural enterprises. The complete development procedure of the formula is fully described in a technical report (Nicolas et al., 2006a). Only the main philosophy is outlined here. The present paper stresses more on the compatibility of the distance approach with odour units, odour rate and percentiles usually applied to assess the odour annoyance zones. A method of validation is tested to adjust the different parameters of the formula to Belgian field reality.

\section{Methodology}

\subsection{Case studies for formula validation}

The proposed formula is inspired by the national guidelines applied in Germany (TA-Luft and VDI), in Holland, in Switzerland, in Quebec, in Austria and in the Flemish part of Belgium (Gent University and Flemish regulation). It exploits the chief assets of each of them: the factor dynamics of German and Flemish methods, the Dutch approach to take the land use categories into account, the type of equation proposed by Austria and the order of magnitude of distances calculated by Austrian, Swiss and Dutch guidelines.

The formula is validated on 43 farms, of which 21 piggeries and 22 poultry facilities, distributed on the whole

Walloon territory, with various land use occurrences. Table 1 shows the breakdown of studied cases according to the breeding type.

The different cases are sampled so that about all the livestock management techniques are investigated, e.g. fully or partially slatted floor, thin or deep litter for pigs, litter, open-air or cage housing for poultry. The farm selection ensures also that every natural or forced ventilation system is represented. The number of animals varies from 200 to 4000 for pigs and from 840 to 86000 for poultry.

The final formula concerns neither open-air pig breeding, nor mixed-breeding (e.g. pigs + cows).

\subsection{Validation methodology}

The maximum distance of odour perception is determined at each field inspection. Then, a typical odour emission rate is issued from an atmospheric dispersion modelling.

The method is inspired by the "sniffing-squad" technique, largely described and discussed in a previous paper (Nicolas et al., 2006b). It consists in trying to delineate the areal extent of odour plume downwind of the livestock buildings. Qualified assessors sniff the odour at different points by a zigzag movement around the axis of the plume. The transitional stages from no odour perception to odour perception are recorded on a detailed map, so that the odour area can be plotted and the maximum odour perception distance can be determined. By definition, the odour concentration at this maximum is one ou $\mathrm{m}^{-3}$ (or, alternatively, one "sniffing unit" to take into consideration the fact that the breeding odour is recognized and not only perceived). As the size of the odour perception area depends also on the meteorological conditions at the time of the measurement, the wind direction, the wind speed and the solar radiation (or cloudiness) are simultaneously recorded. The two last parameters allow determining the atmospheric stability using Pasquill stability class system. Then, a dispersion model, adapted to simulate the odour perception, is used with these meteorological data. The emission rate entered into the model is adjusted until the simulated average isopleth for $1 \mathrm{ou} \mathrm{m}^{-3}$ at about $2 \mathrm{~m}$ height (the height of the human nose) fits the measured maximum perception distance. Such back-calculation is an indirect method of assessing the odour emission rate of diffuse and fugitive sources, like breeding farms. 
Table 1. Cases studied during the validation phase

\begin{tabular}{|l|c|}
\hline \multicolumn{1}{|c|}{ Livestock type } & Number of cases \\
\hline Piggeries & 9 \\
\hline Farrow-to-finish (closed-circuit) & 10 \\
\hline Fattening & 2 \\
\hline Sows with piglets & 13 \\
\hline Poultry & 5 \\
\hline Fattening chickens & 4 \\
\hline Laying hens & \\
\hline Ducks (breeding or force-feeding) & \\
\hline
\end{tabular}

That outcome can firstly be used to estimate the odour emission rate of one "animal-unit" (e.g. one fattening pig) and so, to compare the global distance methodology to a more sophisticated technique using odour emission rates.

But, for validation purpose, the total emission rate is also used to estimate an "annoyance zone", valid for average meteorological conditions for the studied site. Such zone corresponds to a given 1-h odour concentration at a given percentile. For example, the 98th percentile for $5 \mathrm{ou} \mathrm{m}^{-3}$ represents the contour line delimiting the zone at the ground level inside which that concentration is exceeded more than $2 \%$ in the year. It may be noted $C_{98 ., 1-h}$ $<5 \mathrm{ou}_{\mathrm{E}} \mathrm{m}^{-3}$. The calculated "annoyance" zone can be compared to the zone delimited by the separation distance estimated by the formula.

Different types of atmospheric dispersion models may be used both for back-calculating the odour emission rate and for evaluating the percentile. In the frame of the present study, a simple bi-Gaussian model adapted to odour dispersion (Tropos, from Odotech, Canada) was used. It implements a meandering algorithm splitting the Gaussian time averaged plume into an instantaneous smaller meandering plume. The movement of the instantaneous plume allows coping with the odour concentration fluctuations. The model neglects the topography, but is sufficient for a coarse validation of the formula. The percentiles are calculated for average climatic conditions available for the synoptic station of the Belgian Royal Meteorological Institute (BRMI) closest to the farm. Data are available for nine such stations in the Walloon region which covers a total surface of about $17000 \mathrm{~km}^{2}$. The meteorological file is a set of occurrences of combinations 'wind speed class/wind direction sector/stability class' on the basis of 30-40 years of hourly observations.

\section{Results and discussion}

\subsection{Broad outline of the formula}

The separation distance $D$ (in meters) is calculated by the following formula:

$$
D=\alpha f_{\mathrm{D}} f_{\mathrm{R}}\left(N f_{\mathrm{A}} f_{\mathrm{T}}\right)^{n}
$$

where $\alpha$ is a "fitting factor" (see below), $f_{\mathrm{D}}$ is the dispersion factor, $f_{\mathrm{R}}$ is the land use category factor, $N$ is the number of animals, $f_{\mathrm{A}}$ is the species factor, $f_{\mathrm{T}}$ is the technical factor and $n$ is an exponent.

This kind of model is mainly defined by assumptions of assessment of odour annoyance acceptability and of hemispherical odour dispersion.

- As for many other guidelines, $D$ is a distance of annoyance acceptability, and not a distance of odour perception or of odour recognition. That means that $D$ integrates all the odour dimensions (the so-called FIDOL scheme, as suggested by Watts and Sweeten, 1995): frequency of occurrence, intensity, duration, offensiveness or hedonic tone and chiefly the social tolerance of the local resident, i.e., the type of land use and the nature of human activities in the vicinity of the odour source.

- Hemi-spherical odour dispersion implies a circle shaped annoyance zone when projected on a 2D-map. Such hypothesis is poorly reliable since footprint never shows a pure circular odour pattern around the source. However, that bull's-eye approach is sufficient for a coarse estimation for regulating purpose. Important features of our specific model are the following. 
- Parameter $\alpha$ can be adjusted to fit the observed Belgian situations.

- All the parameters are multiplicative factors, so that any variation range (from 0 to 1 , from 0 to $10, \ldots$ ) can be chosen for them, the final distance will be adjusted by $\alpha$. Moreover, with multiplicative factors, sensitivity analyses are easier.

- The specific choice is to select a variation range of 0-2 for every factor; in such manner that 1 is the "average" situation for Wallonia. The advantage is that coarse typical distance estimation for $N$ animals is easily calculated by putting all factors to 1 . Specific cases are then appraised by "correcting" those factors upwards for worse livestock techniques or environmental conditions or downwards for better conditions.

- The expression between brackets is the emission feature, depending on the animals and the activities inside the farm itself. It has the same meaning as odour emission rate and may be compared to ou $\mathrm{s}^{-1}$. Other factors and the exponent depend on atmospheric dispersion and odour acceptability in the surroundings, i.e., the immission part of the odour exposition.

- Particularly, exponent $\mathrm{n}$ of the power law copes for the geometric plume expansion downwind the source. Assuming an ideal hemi-spherical dispersion should lead to an exponent of 1. Applying bi-Gaussian model with a linear evolution of $t / 3$ he standard deviations with the downwind distance shows that, at ground level, the concentration is proportional to the square root of the emission rate. So, a unique value of 0.5 is selected for exponent $n$.

Factor $f_{\mathrm{A}}$ acknowledges the fact that some species produce more odour than others. Odour generation for each animal is expressed with respect to the fattening pig ( $>70 \mathrm{~kg}$, i.e., at finishing stage) for which $f_{\mathrm{A}}=1$, e.g. $f_{\mathrm{A}}=1.8$ for sow with piglets, $f_{\mathrm{A}}=0.025$ for fattening chicken, $f_{\mathrm{A}}=0.033$ for laying hen. The order of magnitude of the equivalence factor is about the same as the one of many other guidelines.

Factor $f_{\mathrm{T}}$ is the more complete one. It is a measure of the technical equipment of the livestock building and of the breeding management. It is the product of a ventilation factor $f_{\mathrm{v}}$ (ranging from 0.3 to 1.4), a manure type, storage and treatment factor $f_{\mathrm{LSE}}\left(0.4-2.9\right.$ for pigs and 0.5-2.4 for poultry) and a feeding factor $f_{\mathrm{F}}(1-1.15)$. The technical factor is an important one, its dynamics (the range of its variation) allows a huge variability of the calculated distances (from 1 to about 7 for pig production). It may stimulate the farmer to adopt breeding techniques which reduces the odour generation.

The dispersion factor $f_{\mathrm{D}}$ expresses the surface roughness of the environment: 0.8 for significant hills and valleys or relatively high and agglomerated buildings, 1 for medium relief with smooth undulating hills or small scattered buildings and 1.2 for low relief without any sharp discontinuity. It must be pointed out that Wallonia relief is not strongly perturbed, like mountain areas in Austria or in Switzerland. So, the dynamics of $f_{\mathrm{D}}$ remains limited.

The $f_{\mathrm{R}}$ factor refers to 3 land use categories in Wallonia: agricultural zone $\left(f_{\mathrm{R}}=0.8\right)$, rural character residential zone $\left(f_{\mathrm{R}}=1\right)$ and housing or leisure zone $\left(f_{\mathrm{R}}=1.5\right)$. The land use category factor does not refer to the livestock building location, but to the house of the first actual or potential resident with annoyance sensitivity for pig odour depending on his life quality expectation.

Table 2 summarizes the parameters and their numerical ranges.

Table 2. Summary of model parameters and their numerical ranges

\begin{tabular}{|l|l|l|}
\hline \multicolumn{1}{|c|}{ Factor symbol } & \multicolumn{1}{c|}{ Meaning } & \multicolumn{1}{c|}{ Value or range } \\
\hline$\alpha$ & Fitting factor & 5 (constant value) \\
\hline$n$ & Exponent & 0.5 (constant value) \\
\hline$f_{\mathrm{A}}$ & Species factor & $\begin{array}{l}1=\text { fattening pig } \\
0.2-1.8 \text { for pigs } \\
0.025-0.050 \text { for poultry }\end{array}$ \\
\hline$f_{\mathrm{T}=f_{\mathrm{V}} f_{\mathrm{LSE}} f_{\mathrm{F}}}$ & & \\
\hline$f_{\mathrm{V}}$ & Technical factor & $0.3-1.4$ \\
\hline$f_{\mathrm{LSE}}=f_{\mathrm{L}} f_{\mathrm{S}} f_{\mathrm{E}}$ & Ventilation factor & \\
\hline$f_{\mathrm{L}}$ & Manure factor & $0.6-1.6$ \\
\hline$f_{\mathrm{S}}$ & Manure type & $0.7-2.0$ \\
\hline$f_{\mathrm{E}}$ & Manure storage & $0.7-1.4$ \\
\hline$f_{\mathrm{F}}$ & Manure treatment & $1.0-1.15$ \\
\hline$f_{\mathrm{D}}$ & Feeding factor & $0.8-1.2$ \\
\hline$f_{\mathrm{R}}$ & Dispersion factor & $0.8-1.5$ \\
\hline
\end{tabular}




\subsection{Relationship with odour emission rate}

The assessment of industrial odour impact zone is generally conducted in two steps. During a first phase, the global odour emission rate is measured by any method (dynamic olfactometry, sniffing-squads ...). Then, a second phase consists in computing a percentile curve for that odour emission rate and average climatic conditions, using an atmospheric dispersion model. Alternatively, most livestock guidelines use empirical formulas deducing the final distance (or buffer zone) directly from the number and type of animals, in one step, without passing through the odour emission rate.

As mentioned above, the present work tries to make compatible both approaches. The expression between brackets in Eq. (1) may be compared to an odour emission rate.

A rough way of converting that expression into ou $\mathrm{s}^{-1}$ is to assess the odour emission rate of 1 equivalent fattening pig (EFP) which is chosen as animal-unit. For such purpose, a mass of $90 \mathrm{~kg}$ is considered for the fattening pig (finishing stage).

A glance over the literature shows a huge range of proposed values: from 0.7 to $450 \mathrm{ou} \mathrm{s}^{-1}$ fattening pig $^{-1}$. Such discrepancies may chiefly be attributed to the evolution of odour measurement methods. Earliest studies or guidelines were based on very low odour emission rate per animal. For instance, Dutch 1985-odour policy (Ministeries van VROM en LNV, 1985) considered $2 \mathrm{ou} \mathrm{s}^{-1}$ for a fattening pig. Later, De Fré (1994) considered that value as underestimated and proposed $5 \mathrm{ou} \mathrm{s}^{-1} \mathrm{EFP}^{-1}$. At the end of nineties and after 2000, odour measurement methods were more standardized, leading e.g. to European EN13725 standard for dynamic olfactometry. Recent investigations on pig or poultry houses report higher values, typically $20 \ldots 60 \mathrm{ou} \mathrm{s}^{-1} \mathrm{EFP}^{-1}$ for pig production and $10 \ldots .20 \mathrm{ou} \mathrm{s}^{-1} \mathrm{EFP}^{-1}$ for poultry facility. A significant number of papers are found about livestock odour emission. Guingand (2003) presents the results of a literature survey showing that odour emission ranges from 0.7 to 100 $\mathrm{ou} \mathrm{s}^{-1}$ for the equivalent of a 90-kg pig. Defoer and Van Langenhove (2003) measured mean values of $63 \mathrm{ou} \mathrm{s}^{-1}$ for fattener in closed pig farms and $21 \mathrm{ou} \mathrm{s}^{-1}$ for fattener in fattener farms. Müller et al. (2003) give values from 2 to $20 \mathrm{ou} \mathrm{s}^{-1}$ for ducks, hens and broilers converted to 1 fattening pig. Hayes et al. (2006) give also values for poultry production units which could be converted into $41-48 \mathrm{ou} \mathrm{s}^{-1} \mathrm{EFP}^{-1}$.

Another cause of discrepancies in emission values is the fact that the odour is not only proportional to the animal mass, but depends also, for an equivalent mass, on its type and on the breeding management technique. In the formula, the conversion by factors $f_{\mathrm{A}}$ and $f_{\mathrm{T}}$ is an attempt to correct the initial odour emission rate derived for fattening pig, but with many uncertainties.

For further validation purpose, the average value of $20 \mathrm{ou} \mathrm{s}^{-1} \mathrm{EFP}^{-1}$ is considered.

\subsection{Odour annoyance criterion}

The development and the selection of a reliable odour annoyance criterion are complex. Many different techniques for developing such a criterion exist including questionnaires and telephone surveys (Hayes et al., 2006). In many countries, the exposure criteria to be respected near the receptor is translated into numerical value as an odour concentration (in ou $\mathrm{m}^{-3}$ ) with $1 \mathrm{~h}$ averaging and a given percentile compliance. That is a makeshift solution, which could be questionable. Schauberger et al. (2005) conclude that meteorological statistical observations are not sufficient to evaluate buffer zones around odour sources. Results are not coherent with various odour statistics and odour impact criteria should be based not only on statistical limits, but also on annoying potential of odour due to the behaviour of the neighbours. Nevertheless, some works aimed at establishing reliable dose-effect relationships (see e.g. Misselbrook et al., 1993; Jiang, 2000; Hayes et al., 2006). Miedema et al. (2000) deduced from survey measurements the following relationship between exposure and annoyance.

$$
\% \mathrm{HA}=K\left[\log \left(C_{98}\right)\right]^{2}
$$

where \%HA is the percentage of highly annoyed persons, $K$ depends on the odour pleasantness and is around $10 . . .12$ for pig farm odour, $C_{98}$ is concentration at 98 th percentile.

For example, choosing $10 \%$ of highly annoyed persons as criterion to delimitate the buffer zone around livestock buildings leads to a concentration of $8-10 \mathrm{ou} \mathrm{m}^{-3}$ for 98 th percentile. 
Another interesting tool to select the adequate annoyance criteria is suggested in Watts and Sweeten (1995) and Schauberger et al. (2001). It is summarized in Fig. 1 which defines, both for rural and for urban zones, odour concentration threshold versus exceeding time probability for livestock odours.

According to that scheme, in rural zones, the limit of acceptable concentration for $2 \%$ of time probability (98th percentile) should be $5.4 \mathrm{ou} \mathrm{m}^{-3}$. Such order of magnitude is also proposed in the EPA report on odour impacts of intensive agriculture (Van Harreveld and Jones, 2001); the suggested limit value for existing pig production units should be $C_{98,1-\mathrm{h}}<6.0 \mathrm{ou}_{\mathrm{E}} \mathrm{m}^{-3}$.

According to actual trends, the proposed odour impact criterion is a combination of odour concentration threshold and its corresponding exceeding time probability. Fig. 1 clearly shows that, for regulatory purpose, different equivalent combinations may be proposed. For instance, the limit of acceptable impact for rural zone could be defined by all points lying on the above line, e.g. $C_{98,1-\mathrm{h}}<5.4 \mathrm{ou}_{\mathrm{E}} \mathrm{m}^{-3}$ or $C_{98,1-\mathrm{h}}<2.2 \mathrm{ou}_{\mathrm{E}} \mathrm{m}^{-3}$ or $C_{90,1-\mathrm{h}}<1.1 \mathrm{ou}_{\mathrm{E}} \mathrm{m}^{-3}$.

We compared the different distances calculated by Tro-pos dispersion model for a typical odour emission rate of $20000 \mathrm{ou} \mathrm{s}^{-1}$ at $5 \mathrm{~m}$ height and the climate of Uccle (Brussels, Belgium). Average distance is estimated as the radius of the circle of area equivalent to the real area delimited by the calculated percentile. Fig. 2 shows isodistance curves (in meters) in the plane odour concentration versus percentile value.

Figure shows that percentile 98 for $7 \mathrm{ou} \mathrm{m}^{-3}$ (point 1) and percentile 94 for $2 \mathrm{ou} \mathrm{m}^{-3}$ (point 2) represent nearly equivalent zones with a mean radius of $300 \mathrm{~m}$ around the source. Point 3 at $C_{97.1-\mathrm{h}}<9 \mathrm{ou}_{\mathrm{E}} \mathrm{m}^{-3}$ and point 4 at $C_{89.1-\mathrm{h}}$ $<2.0 \mathrm{ou}_{\mathrm{E}} \mathrm{m}^{-3}$ correspond also to the same mean distance of $200 \mathrm{~m}$. Considering e.g. $5 \mathrm{ou} \mathrm{m}^{-3}$ as the annoyance threshold and knowing that $1 \mathrm{ou} \mathrm{m}^{-3}$ is the perception threshold, the former reasoning shows that perceiving the odour during $9 \%$ of annual time at a distance of about $300 \mathrm{~m}\left(C_{91.1-\mathrm{h}}<1.0 \mathrm{ou}_{\mathrm{E}} \mathrm{m}^{-3}\right.$, point 5$)$ corresponds approximately to feeling an annoyance at the same distance during $2 \%$ of time $\left(C_{98.1-\mathrm{h}}<5.0 \mathrm{ou}_{\mathrm{E}} \mathrm{m}^{-3}\right.$, point 6$)$.

Fig. 1. Relationship between percentage of annual time of unacceptable impact and odour concentration limit value (inspired by Watts and Sweeten, 1995 and by Schauberger et al., 2001 ).

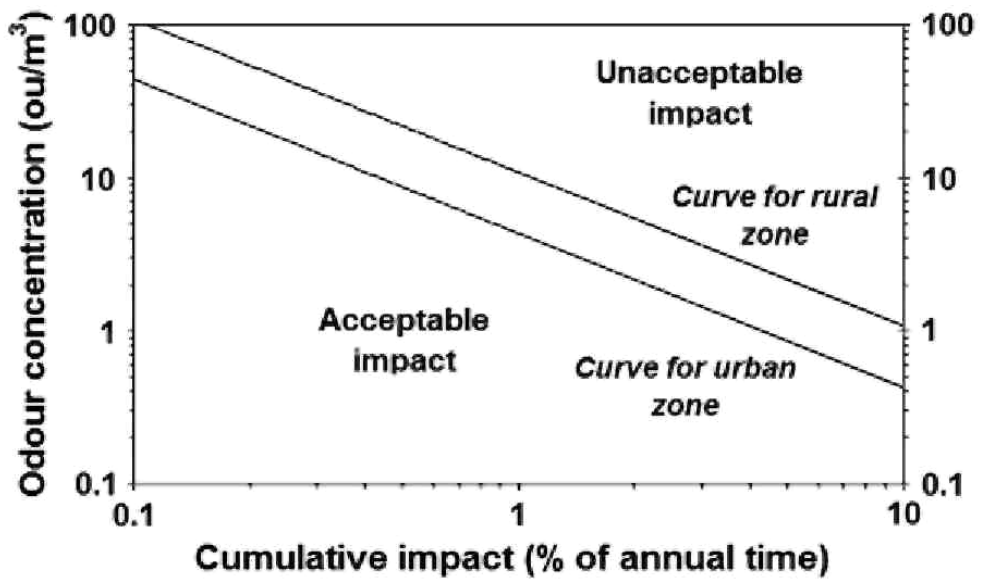

Recent policies would tend to propose the 98th percentile as exposure criteria, because this value can be seen as a compromise, reflecting the relatively rare times with high exposure, which are more determining, but being based on a sufficient amount of hours in a year (Van Harreveld et al., 2001). The choice of the right corresponding odour concentration value depends on the offensive character of the odour. A study conducted in Ireland (Hayes et al., 2006) concludes that impact criterion $C_{98.1-\mathrm{h}}<9.7 \mathrm{ou}_{\mathrm{E}} \mathrm{m}^{-3}$ could be implemented for poultry production units.

For the present study, the validation work is carried out with $C_{98.1-\mathrm{h}}<10.0 \mathrm{ou}_{\mathrm{E}} \mathrm{m}^{-3}$, but the methodology can easily be transposed to other odour concentrations. For example, an impact criterion $C_{98.1-\mathrm{h}}<6.0 \mathrm{ou}_{\mathrm{E}} \mathrm{m}^{-3}$ for piggeries could be discussed, while keeping $C_{98.1-\mathrm{h}}<10.0 \mathrm{ou}_{\mathrm{E}} \mathrm{m}^{-3}$ for poultry facilities.

Validation of distance formula in Wallonia takes advantage of the homogeneity of the investigated territory, which is a specificity of Walloon region with respect to larger regions or countries. The whole area covers only 
$17000 \mathrm{~km}^{2}$, with highest point at $694 \mathrm{~m}$, and is characterized by a quite homogeneous temperate oceanic climate, without any littoral zone, so that prevailing wind always are SW-NE, as illustrated by wind rose in Fig. 3.

Fig. 4 shows the shapes and relative sizes of 98th percentile for 6 different stations of South of Belgium. Choosing Uccle as single average station for whole Wallonia leads to about $9 \%$ error on mean distance. For rough validation purpose, such error is acceptable. So next tests are conducted only with Uccle climate.

\subsection{Validation results}

The formula is validated globally, by comparing the final distance estimated or measured by different approaches. It means that the structure of Eq. (1) is not recalled into question.

The different factors are adjusted so to reflect the general feeling of field operators about the perceived odour, its hedonic tone and the maximum distance of perception for the meteorological condition of the measurement day.

Animal factor $f_{\mathrm{A}}$, firstly determined on the basis of expert opinions, is adjusted for some species after the field campaign. For example, $f_{\mathrm{A}}$ is definitively put to 0.050 for breeding ducks and to 0.033 for force-feeding ducks. A possible justification of the relatively less intense odour for force-feeding ducks could be simpler feeding, more diluted liquid manure and short duration of force-feeding.

Technical factor $f_{\mathrm{T}}$ is more difficult to adjust.

Concerning ventilation part $f_{\mathrm{V}}$, field operators firstly carried out spot measurements of the flow rate by microanemometer in the exhaust duct of forced ventilation system. Nevertheless, such spot assessment may just be used to verify an order of magnitude, but cannot be used to evaluate the global waste airflow of the whole farm. Anyway, information on the general flow regulation scheme according to the number of animals and the outdoor conditions is more valuable than spot measurements. Moreover, it is impossible to measure flow rate for natural ventilation. So, the validation results concern more the global feeling of the operators when walking around the farm.

Main outcomes are close to the conclusions of other guidelines.

Generally, forced ventilation system is preferred to natural ventilation, in any case if waste air exit is at least at $0.5 \mathrm{~m}$ above roof ridge. The ventilation system of housings might be designed so that waste air is exhausted when its temperature is above outdoor temperature.

Fig. 2. Contours of equivalent distances (labelled in $\mathrm{m}$ ) in the plane odour concentration versus percentile value for average climate of Uccle (Brussels) and odour emission rate $=20000 \mathrm{ou} \mathrm{s}^{-1}$.

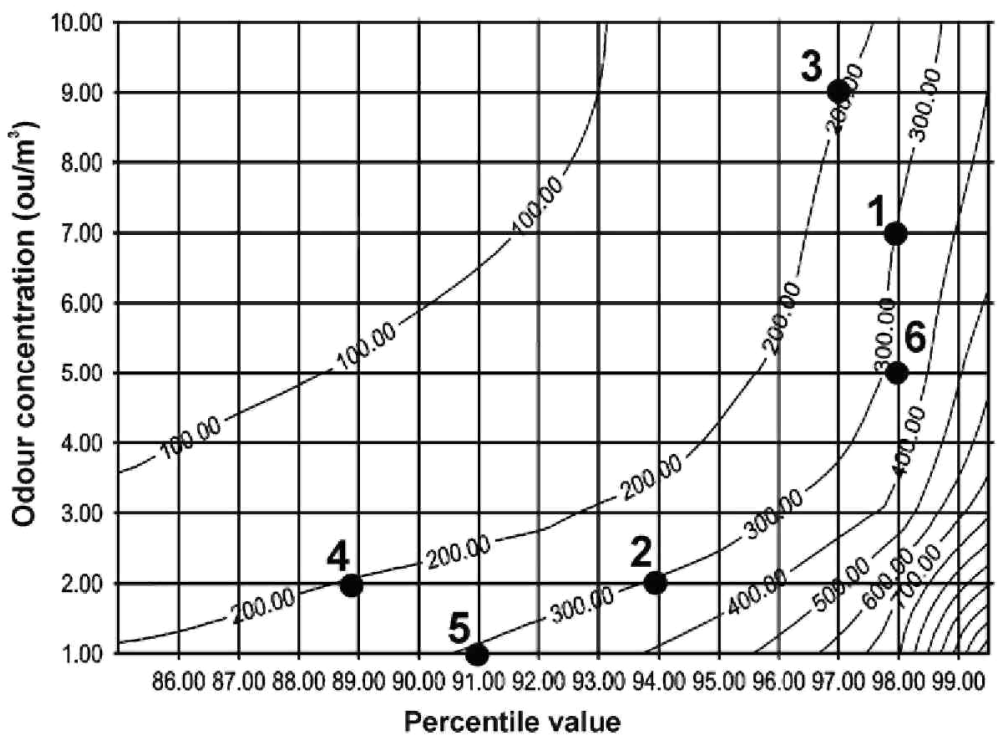


The manure part $f_{\mathrm{LSE}}$ of technical factor is considered separately for piggeries and for poultry facilities. Definitive $f_{\text {LSE }}$ values are difficult to propose because odour often results from less objective impressions, like hygiene lack.

For pigs, the best case is partially slatted floor, with daily manure evacuation from local storage below the pens to an external covered storage container. The worst case is litter on solid concrete floor, removed by scrapers less than once a week and stored in an external open container. For poultry, less odour is generated when the dung is dried by an heating system and transported to a covered store by conveyor belts.

Dispersion factor $f_{\mathrm{D}}$ has less influence than other ones on the final distance. For about all the studied cases, the livestock buildings are indeed situated in rather flat areas.

On the other hands, wind frequency distribution patterns are often put forward to explain the variations of odour plume shape and size. Some guidelines propose to compute a meteorological factor based on the frequency of calm winds. In the case of Wallonia, as mentioned before, the climate homogeneity makes such factor less relevant.

However an interesting alternative could be to draw around the breeding housing an ellipse rather than a circle. As percentiles always take the form of ellipse-like curves (see Fig. 4), a good suggestion should be to draw an ellipse elongated in the prevailing wind direction and with major axis and minor axis lengths, respectively, 1.2D and $0.8 \mathrm{D}$, with $D$ equal to the mean calculated separation distance.

The land use category factor $f_{\mathrm{R}}$ is examined by measuring the actual distance between the farm and the first resident for different land use categories. Table 3 shows the distance statistics for 29 out of the 43 cases (distance was not measured for other ones).

Average distances are rather small: $146 \mathrm{~m}$ for piggeries and $199 \mathrm{~m}$ for poultry facilities, but with a large standard deviation, showing that real situations may considerably vary from one case to another.

Real distance observations suggest using the $f_{\mathrm{R}}$ factor for the first potential resident rather than the first real one. The building situation may indeed vary after the moment of the expert assessment. A house may be built later at a location nearer the farm.

Fig. 3. Typical wind rose of the investigated territory (data from Uccle, Brussels).

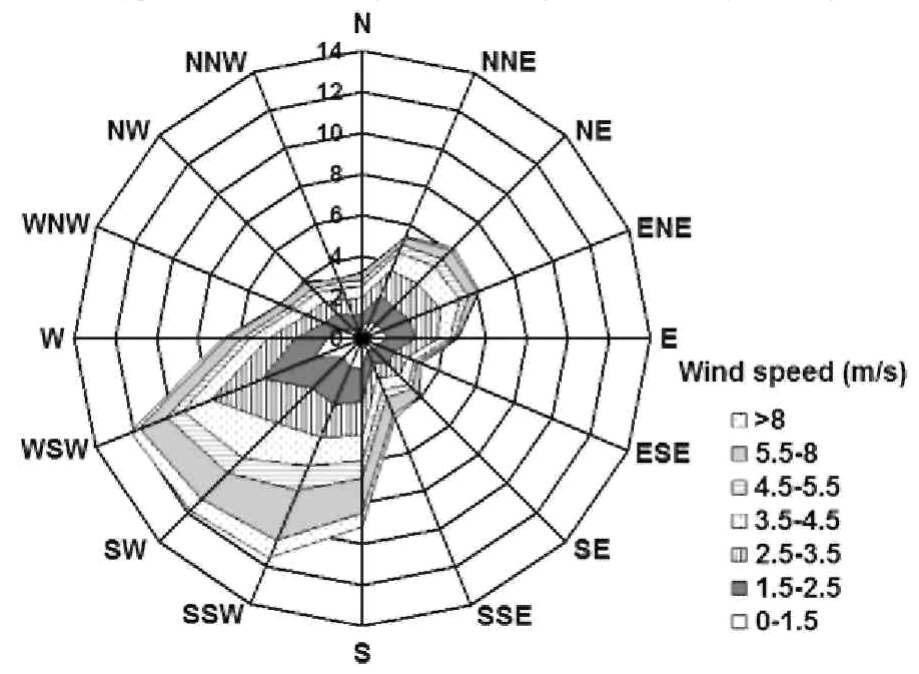

For the 29 cases considered in Table 3, average "real" distance for all cases and all breeding types is $174 \mathrm{~m}$, but is reduced to $154 \mathrm{~m}$ when considering the first "virtual" resident of a building zone.

Of course, that part of the validation phase did not aim at adjusting the annoyance distance to the actual observed distance of the first resident. However, such observations allow appreciating the severity of different guidelines 
regarding real field situation in Wallonia. Main results show that $60 \%$ of the studied farms should respect the eight considered foreign guidelines, $30 \%$ should only respect the less severe ones (Holland, Switzerland or Austria) and only $10 \%$ should respect no guidelines at all.

Finally the most significant contribution of the validation work is the adjustment of $\alpha$ factor. All other factors are particularly useful to adapt the separation distance to the particular case. They have different sensibilities on the final distance, but for all the 43 visited livestock farms, the impact of those factors on the distance is rarely above $100 \%$. To adjust the absolute distances to real field annoyance impression, the choice of $\alpha$ factor is essential.

Fig. 4. Drawing of 98th percentile for 1 ou $\mathrm{m}^{-3}$ for 6 different stations of south of Belgium.

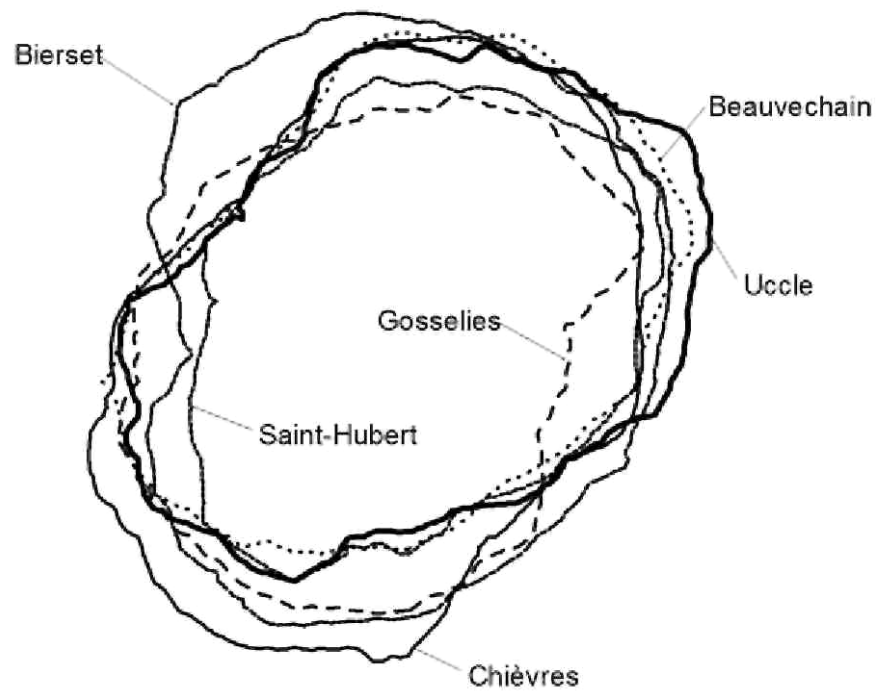

Table 3. Statistics of real measured distances between livestock buildings and nearest resident

\begin{tabular}{lllll}
\hline \multicolumn{1}{c}{$\begin{array}{c}\text { Land use category of the nearest } \\
\text { resident }\end{array}$} & \multicolumn{1}{c}{ Statistics } & \multicolumn{2}{c}{ Breeding type } \\
\cline { 2 - 5 } & & Pigs & Poultry & Total \\
\hline Agricultural zone & Number of cases & 6 & 8 & 14 \\
& Average distance $(\mathrm{m})$ & 191 & 148 & 166 \\
Rural character & Standard deviation $(\mathrm{m})$ & 150 & 138 & 139 \\
residential zone & Number of cases & 5 & 7 & 12 \\
& Average distance $(\mathrm{m})$ & 158 & 258 & 216 \\
Housing and leisure zone & Standard deviation $(\mathrm{m})$ & 133 & 405 & 314 \\
& Number of cases & 3 & 0 & 3 \\
All zones & Average distance $(\mathrm{m})$ & 39 & - & 39 \\
& Standard deviation $(\mathrm{m})$ & 23 & - & 23 \\
& Number of cases & 14 & 15 & 29 \\
& Average distance $(\mathrm{m})$ & 146 & 199 & 174 \\
& Standard deviation $(\mathrm{m})$ & 134 & 289 & 225 \\
\hline
\end{tabular}

A first way of assessing $\alpha$ is considering general situation, independently of particular cases. As above mentioned, the most typical situation for Walloon Region is using Eq. (1) with all factors (excepted $\alpha$ ) equal to 1. Hence, distance $D$ is $\alpha$ times the square root of the number of fattening pigs. Assuming that each fattening pig generates an odour emission rate of $20 \mathrm{ou} \mathrm{s}^{-1}$, it is possible to establish a relationship with 98th percentile at 10 $\mathrm{ou} \mathrm{s}^{-1}$ (the chosen annoyance criteria) by entering $20 \mathrm{~N}$ as global emission rate into the dispersion model. To make compatible the distance calculated by Eq. (1) with the average distance estimated by the radius of the circle of area equivalent to the real area delimited by the calculated percentile, $\alpha$ must be 4.5 for 100 pigs and 6 for 2000 pigs. A value of 5 could be a good compromise. 
An alternative way of adjusting $\alpha$ is using field observations. This is applied for 28 out of the 43 studied cases. For each of those 28 facilities, distance $D$ is calculated by introducing in Eq. (1) the farm specific factors, but without using $\alpha$ in the formula. Concurrently, distance may be evaluated on the basis of 98th percentile for $10 \mathrm{ou}$ $\mathrm{s}^{-1}$ entering into the model the global odour emission rate deduced from the "sniffing-squad" assessments. Then the two distances are compared. Table 4 shows those calculation results. Specific parameters used for Eq. (1) for each case are not presented here because each studied case generally concerns a combination of different livestock buildings, with different factor values.

Figs. 5 and 6 show scatterplots of the two distances and the regression line passing through the origin respectively for pig and for poultry farms.

$R$-Squared values of the regressions are relatively low, especially for piggeries, but that could be attributed to the uncertainties of the odour emission rate estimated by the sniffing-squad method when only one field measurement is performed. In spite of the poor regression quality, it is encouraging to observe that the proportionality coefficient between the two distances in both cases is close to value 5 firstly estimated.

Fig. 5. Relationship between distances calculated by Formula (1) and by dispersion model for piggeries.

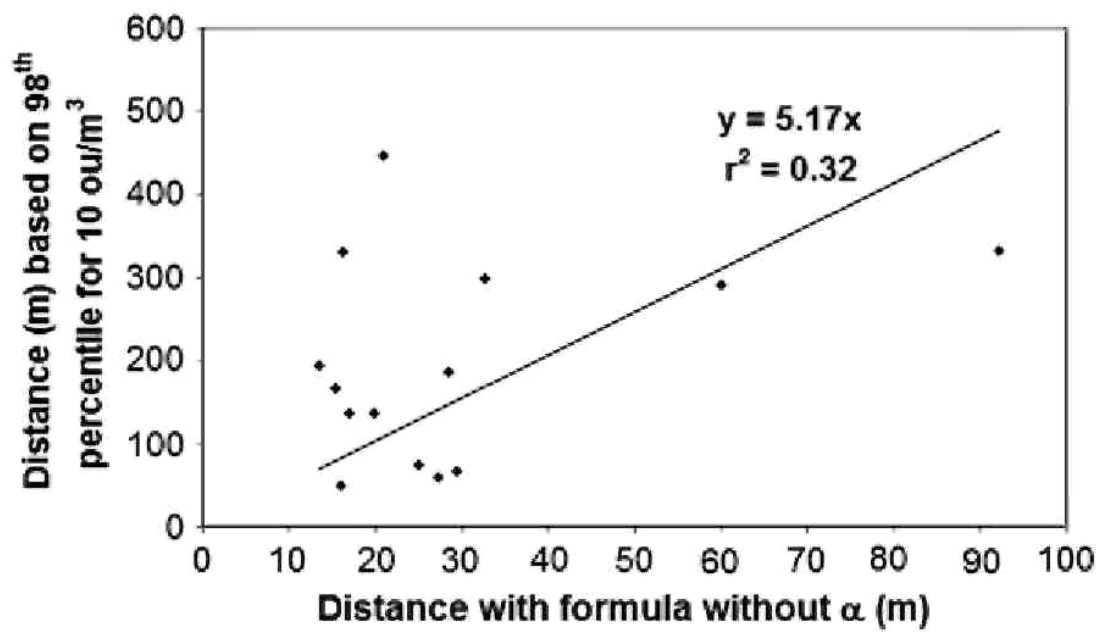

Fig. 6. Relationship between distances calculated by Formula (1) and by dispersion model for poultry facilities.

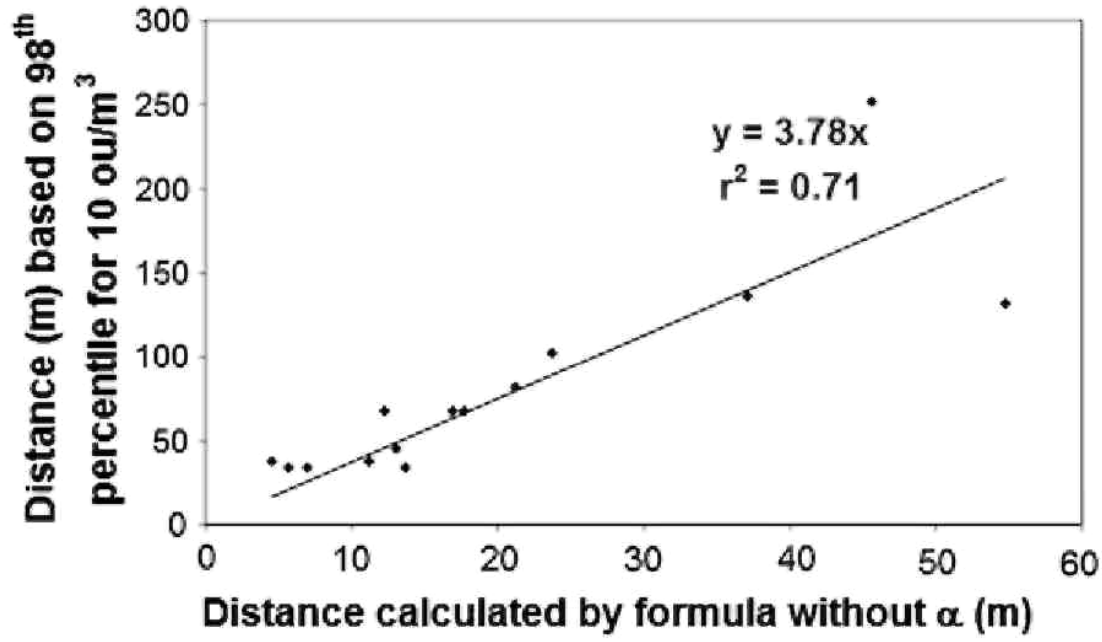


Table 4. Summary of calculation results for model validation

\begin{tabular}{|c|c|c|c|c|}
\hline Type & $N \times f_{\mathrm{A}}$ & Odour emission rate $\left(\right.$ ou s $\left.^{-1}\right)$ & $C_{98.1-\mathrm{h}}<10$ ou $\mathrm{m}^{3}$ distance $(\mathrm{m})$ & $D$ by Eq.(l) without $\alpha(\mathrm{m})$ \\
\hline \multirow[t]{14}{*}{ Pigs } & 1496 & 47124 & 298 & 33 \\
\hline & 287 & 16065 & 137 & 17 \\
\hline & 784 & 5355 & 68 & 29 \\
\hline & 475 & 21000 & 166 & 15 \\
\hline & 455 & 55332 & 332 & 16 \\
\hline & 360 & 24633 & 187 & 28 \\
\hline & 1025 & 6426 & 75 & 25 \\
\hline & 180 & 26000 & 195 & 13 \\
\hline & 3150 & 55432 & 332 & 92 \\
\hline & 251 & 2800 & 50 & 16 \\
\hline & 196 & 4200 & 60 & 27 \\
\hline & 456 & 16065 & 137 & 20 \\
\hline & 3000 & 45450 & 291 & 60 \\
\hline & 679 & 106600 & 447 & 21 \\
\hline \multirow[t]{14}{*}{ Poultry } & 330 & 2132 & 46 & 13 \\
\hline & 2150 & 16000 & 136 & 37 \\
\hline & 445.5 & 5330 & 68 & 18 \\
\hline & 1100 & 10660 & 103 & 24 \\
\hline & 2706 & 37000 & 252 & 46 \\
\hline & 450 & 7462 & 82 & 21 \\
\hline & 60 & 533 & 34 & 6 \\
\hline & 25.2 & 1000 & 38 & 11 \\
\hline & 150 & 3731 & 68 & 12 \\
\hline & 487.5 & 5330 & 68 & 17 \\
\hline & 125 & 1066 & 38 & 4 \\
\hline & 130 & 500 & 34 & 14 \\
\hline & 62.5 & 500 & 34 & 7 \\
\hline & 3000 & 15290 & 132 & 55 \\
\hline
\end{tabular}

\section{Discussion}

In the final version of Eq. (1), proposed as a guideline project for the Walloon Government, $\alpha$ coefficient has the value 5. That is a compromise which takes all the studied cases into account and which allows using the same formula both for pig or poultry facilities.

However, an alternative proposal could be to use two different formulas, one adapted for pigs and the other for poultry.

For pigs, the annoyance criterion the more often suggested in the literature is $C_{98.1-\mathrm{h}}<6.0 \mathrm{ou}_{\mathrm{E}} \mathrm{m}^{-3}$. Choosing that criterion increases the distance based on percentile calculation on average by about $40 \%$. So, for pigs, $\alpha=7$ could be a more reliable proposal.

For poultry, the annoyance criterion $C_{98.1-\mathrm{h}}<10 \mathrm{ou}_{\mathrm{E}} \mathrm{m}^{-3}$ maybe kept, but Fig. 6 examination suggests $\alpha=3.75 \ldots$ 4.0.

As expected, the field validation phase was essential to refine the initially proposed formula. Previous outcomes seem showing that two different guidelines could be proposed, one for pigs and the other for poultry. Alternatively, a single formula for both breeding types could be proposed, but the species factor $f_{\mathrm{A}}$ should be corrected for poultry, e.g. if $\alpha=7$ for both breeding type, $f_{\mathrm{A}}$ for poultry should be divided by 3 . Such proposal needs more detailed validations with a larger number of odour emission rate estimations on each site. 
Concerning emission factor, expressed in ou s ${ }^{-1} \mathrm{EFP}^{-1}$, Table 4 results confirm the huge range of values found in the literature. Our values vary between 4 and $157 \mathrm{ou} \mathrm{s}^{-1}$ per equivalent fattening pig, with an average value of 32 ou $\mathrm{s}^{-1} \mathrm{EFP}^{-1}$. But, again, such finding needs to be confirmed by further investigation.

A comparison of the presented empirical model with other national guidelines highlights the following observations.

- The proposed species factor is a good compromise between all species factors proposed by guidelines. It should be estimated, together with the number of animals $N$, for an average situation of livestock for a typical year.

- When applying national guidelines to our studied cases, the contribution of the building ventilation factor never exceeds a division by 2 of setback distance between worst situation and ideal situation. Our ventilation factor $f_{\mathrm{v}}$ varies from 0.7 to 1.4 for standard ventilation systems. But a value of $f_{\mathrm{v}}=0.3$ is proposed for recent waste air evacuation and treatment systems through single discharge aperture.

- Concerning manure type and management, national guidelines promote dried litter, frequent removal and storage in closed areas or containers. For some guidelines, the manure factor is included into the global technical factor as one term of a sum, together with ventilation and feeding factors. When those latter factors are bad, the effect of good manure practice is reduced. In our case, the multiplicative approach allows a better assessment of different technical impacts.

- Dispersion factor $f_{\mathrm{D}}$ cannot be compared to corresponding parameters of other guidelines. It is typically adapted to Wallonia situation. Taking wind patterns and orography into account is less relevant for Belgium than for mountainous regions.

- Land use factor $f_{R}$ is also adapted to the official land use categories of Wallonia. It modifies setback distance for $\alpha$ factor 2 between the worst and the best case, as with many other guidelines.

\section{Conclusion}

Setback distance determination models for animal production farms are often based on some general considerations, on some survey and measurement outcomes and on different literature suggestions. In the present case, the initial formula was proposed after a few case studies and discussions with experts. However to be sure that distance models match as closely as possible the field reality, a huge validation work is needed. Present work highlights some possible trends, but more refinements are still possible towards a final guideline version.

\section{Acknowledgements}

Authors are indebted to the Government of Walloon Region (Belgium) for funding the research, to "Filière porcine Wallonne" and "Filière Avicole et Cunicole Wallonne" for their help and judicious advices and to breeders for their kind participation.

\section{References}

Bongers, M.E., Vossen, F.J.H., van Harreveld, A.P., 2001. Geurhinder-onderzoek stallen intensieve veehouderij - samenvatting. Rapport no Vrom01a. PRA OdourNet bv, Amsterdam.

Defoer, N., Van Langenhove, H., 2003. Determination of odour emissions from pig farms for regulatory purposes in Flanders. Horsens, Denmark, 1-4 June 2003. In: Proceeding of the International Symposium on Gaseous and Odour Emissions from Animal Production Facilities, pp. 152-160.

De Fré, R., 1994. Wetgeving en Geurnormen. In: kursus Geurhinder Vlo-mitech, Technologie en Innovatie.

Guingand, N., 2003. Air quality and reduction of slatted floor in growing -finishing pig units. Horsens, Denmark, 1-4 June 2003. In: Proceeding of the International Symposium on Gaseous and Odour Emissions from Animal Production Facilities, pp. 80-87.

Guo, H., Jacobson, L.D., Schmidt, D.R., Nicolai, E.E., Janni, K.A., 2004. Comparison of five models for setback distance determination from livestock sites. Canadian Biosystems Engineering 46, 6.17-6.25.

Hayes, E.T., Curran, T.P., Dodd, V.A., 2006. A dispersion modelling approach to determine the odour impact of intensive poultry production units in Ireland. Bioresource Technology 97, 1773-1779. 
Miedema, H.M.E., Walpot, J.I., Vos, H., Steunenberg, C.F., 2000. Exposure-annoyance relationships for odour from industrial sources. Atmospheric Environment 34, 2927-2936.

Ministeries van VROM en LNV., 1985. Veehouderij en Hinderwet. Den Haag, Ministerie van Volkhuisvesting, Ruimtelijke Ordening en Milieu en Ministerie van Landbouw, Natuurbeheer en Visserij, Brochure.

Misselbrook, T.H., Clarkson, C.R., Pain, B.F., 1993. Relationship between concentration and intensity of odours for pig slurry and broiler houses. Journal of Agricultural Engineering Research 55, 163-169.

Müller, H.J., Brunsch, R., Hörnig, G., Jelinek, A., 2003. Odour and ammonia emissions from poultry houses with different keeping and ventilation systems. Horsens, Denmark, 1-4 June 2003. In: Proceeding of the International Symposium on Gaseous and Odour Emissions from Animal Production Facilities, pp. 172-179.

Nicolas, J., Cobut, P., Otte, B., 2006a. Finalisation et validation d'une formule de calcul de la distance minimale d'implantation des porcheries et des poulaillers applicable en Région wallonne Internal technical report ULg-feb. 2006.

Nicolas, J., Craffe, F., Romain, A.C., 2006b. Estimation of odour emission rate from landfill areas using the method of sniffing team campaigns. Waste Management 26, 1259-1269.

Preston, K., Furberg, M., 2006. Odour management in British Columbia: review of other jurisdictions and recommendations. In: Proceedings of the WEF/AWWA Odors and Air Emissions 2006 Hartford, Connecticut, USA

Schauberger, G., Piringer, M., Petz, E., 2001. Separation distance to avoid odour nuisance due to livestock calculated by the Austrian odour dispersion model (AOMS). Agriculture Ecosystems \& Environment 87, $13-28$.

Schauberger, G., Piringer, M., Petz, E., 2005. Sensitivity analyses of dispersion models to assess odour nuisance: a qualitative comparison with complaint statistics. In: 17th International Congress of Biome-teorology 5-9 Sept, 2005, Garmisch-Partenkirchen.

Van Harreveld, A.P., Jones, N., 2001. Odour impact and odour emission control measures for intensive agriculture, Final Report, Environmental Protection Agency, OdourNet UK Ltd., p. 145.

Van Harreveld, A.P., Jones, N., Stoaling, M., 2001. Anon, assessment of community response to odorous emissions. R\&D Technical Report P4-095. Environment Agency, WRc Document Distribution Centre, United Kingdom, 2002. Available from: www.environment-agency gov.uk.

VDI, 2001. VDI 3474 Emission control livestock farming odorants - VDI-Richtlinien-Handbuch Reinhaltung der Luft, Band 3.

Watts, P.J., Sweeten, J.M., 1995. Toward a better regulatory model for odour. In: Proceedings of the Feedlot Waste Management Conference Queensland, Australia. 